\title{
Transcription profiling of early responses to hemorrhagic fever in
} rhesus macaque

\author{
M Djavani*1,2, O Crasta1,2, JC Zapata ${ }^{1,2}$, Z Fei ${ }^{1,2}$, O Folkerts ${ }^{1,2}$, B Sobral ${ }^{1,2}$, \\ J Bryant $^{1,2}$, C Pauza ${ }^{1,2}$, I Lukashevich ${ }^{1,2}$ and MS Salvato ${ }^{1,2}$
}

Address: ${ }^{1}$ Institute of Human Virology, University of Maryland Biotechnology Institute, Baltechnology Institute, Baltimore, Maryland, 21201, USA and ${ }^{2}$ Virginia Bioinformatics Institute, Blacksburg, Virgina, 24061, USA

* Corresponding author

from 2006 International Meeting of The Institute of Human Virology

Baltimore, USA. |7-2I November, 2006

Published: 21 December 2006

Retrovirology 2006, 3(SuppI I):PI6 doi:10.1 I86/I742-4690-3-SI-PI6

(c) 2006 Diavani et al; licensee BioMed Central Ltd.

Monkeys infected intravenously with a lethal dose of LCMV-WE provide a model for Lassa fever virus infection of man. Like Lassa fever in man, disease begins with flulike symptoms and progresses rapidly to death within two weeks of infection. It is essential to correctly diagnose hemorrhagic fever rather than more benign viral diseases to provide the proper treatment. Microarray analyses were conducted on blood of macaques infected with virulent WE virus, and compared to gene expression in monkeys infected with non-virulent LCMV-ARM. We observed gene expression changes that occur before the viremic stage of the disease, and could potentially serve as biomarkers that discriminate between exposure to a hemorrhagic fever virus and exposure to a benign virus. In particular, transcription analysis revealed an early and severe suppression of the COX2 pathways indicating that disease treatments should avoid COX-inhibitors, like aspirin, and favor pathway stimulators. 